\title{
Learning about "wicked" problems in the Global South. Creating a film-based learning environment with "Visual Problem Appraisal"
}

\section{Loes Witteveen \& Rico Lie}

MedieKultur 2012, 52, 81-99

Published by SMID | Society of Media researchers In Denmark | www.smid.dk The online version of this text can be found open access at www.mediekultur.dk

The current complexity of sustainable development in the Global South calls for the design of learning strategies that can deal with this complexity. One such innovative learning strategy, called Visual Problem Appraisal (VPA), is highlighted in this article. The strategy is termed visual as it creates a learning environment that is film-based. VPA enhances the analysis of complex issues, and facilitates stakeholder dialogue and action planning. The strategy is used in workshops dealing with problem analysis and policy design, and involves the participants "meeting" stakeholders through filmed narratives. The article demonstrates the value of using film in multi-stakeholder learning environments addressing issues concerning sustainable development.

Key words

Visual learning; multi-stakeholder learning environment; complex/wicked problems; Visual Problem Appraisal (VPA); film/video

\section{Introduction}

In the social sciences and life sciences, complex or "wicked" problems are often the object of study. With wicked problems, such as the existence of climate change, conflict and war, HIV/AIDS, and malaria, stakeholders' education about these problems plays an integral role 
in finding solutions and often precedes the negotiation process, which eventually leads to change. This education about wicked problems and learning gleaned from wicked problem situations have been under study for a considerable length of time (see for instance, Wals, 2007), but few of these approaches have systematically studied the implicit or explicit use of visuals in their learning strategies. This article addresses this gap by explicitly looking at the use of film in a multi-stakeholder learning environment.

The idea of exploring visual learning, and more specifically the use of films in learning strategies, emerged as an answer to cater more effectively for learning on diverse stakeholder perspectives. Visual learning strategies would be an option to consent with Robb (2002, p. 104) that "the moral imperative for giving the poor a voice in the poverty debate is self-evident." Robb formulates this notion in a context that focuses on practices, practitioners and policies transcending the level of project and community initiatives. The challenge of designing visual learning strategies in a context of complex, multi-stakeholder settings articulated the need for a better academic understanding of the potential of visual learning in relation to complex problems.

After a brief explanation of complex (wicked) problems, what follows is a theoretical exploration of visual learning strategies. After this foundation is laid, the article continues to explore the value of using film for learning about wicked problems in multi-stakeholder settings related to sustainable development. Visual Problem Appraisal (VPA) is used as an example of such a visual learning strategy - in this case film-based - to show its potential. In the third section, some considerations about the design, production and use of visual learning strategies are discussed.

\section{Complex problems}

The need for developing innovative learning environments is a consequence of complex societal issues subject to the professional and scientific domain of the life sciences and social sciences. Nowadays, complex problems are also called "wicked problems". Wicked problems are problems that do not have one single solution that is right or wrong, good or bad, or true or false. These are problems in which many stakeholders are involved, all of them framing the problems and issues in a different way. Suggested solutions to wicked problems can therefore often be contradictory. What might seem a solution to one stakeholder could be seen as a deepening of the problem by another one. We follow here the distinction between complex and wicked problems by Ker Rault (2008, p. 23), who qualifies "wicked" problems as complex problems related to social systems and values. Reflecting on the consequent changing role of scientists, Giller et al. (2008) state:

For science to contribute to enabling the poor and/or marginalized to gain a voice in their future use of natural resources, emphasis needs to move away from providing solutions and 
plans for stakeholders to the support of negotiation between stakeholders based on negotiated shared understandings of the problems and opportunities for change (2008, p. 14).

Such types of negotiating or "social dialogue" are promoted for concrete purposes, such as, reclaiming indigenous knowledge or monitoring and evaluation, but increasingly also from a rights-based perspective that all people have a right to be heard, especially when "the main debates take place in documents which they do not write, or in meetings which they do not attend" (Slim et al., 1993, p. 4). Hounkonnou (2001), in his dissertation, also elaborates on connecting to local dynamics when pursuing sustainable development:

\begin{abstract}
Sustainable development - the one which can keep going at the end of an intervention - is only possible if we can connect to the people, listen to their cradle and understand what they are doing, in order to act with them in the same direction. Listening to the cradle does not cost more. On the contrary, linking effectively with the local dynamics helps to improve the efficiency of development action, allowing adequate use of the available resources. The most difficult, however, will be to deconstruct and reconstruct our frames and mentalities, and to help local people regain their confidence they have lost in their own capacities and creativity due to the 'expert culture' (2001, p. 232).
\end{abstract}

Hounkonnou highlights here that "listening to the cradle" may initiate a quest for new "expert" procedures and operations as new strategies are required and for most probably new conflicts will be created as well. Hermans (2005), in his dissertation on actor analysis for water management, complements this line of thinking, where he suggests that actor analysis does not have the direct effect of re-framing problem analysis by water experts but that it "facilitates learning and that provides a channel for interaction between experts and actors" (p. 204). Hermans further elaborates on relations between water experts, policy makers and "actors" assigning each a different yet complementary role and indicating the need to change expert minds in a way that goes beyond "a positive attitude" towards actor analysis (2005, p. 205).

These thoughts outline a background of wicked multi-stakeholder problems in a context of sustainable development and link with challenges for learning, participation and dialogue by professionals, experts, policy makers and other concerned social actors.

\title{
Visual learning strategies
}

In the quest for visual learning strategies and new representational forms of people and events, in a mode that allows audience interpretation for learning, the focus is on film. It is assumed that films have particular qualities to unravel and further enquire into "wicked multi-stakeholder problems". The opportunities for and interest in using film in the social (research) domain are growing, but are not yet the focus of attention, and we agree with Braden (1998), who states: 
The failure of those involved in participatory development to engage with the spread of mass media must be seen as a lost opportunity [...]. It has led to a lack of imagination in the use of the technological by-products of mass media, such as audio and video recorders by development practitioners. The development of 'good practices' in relation to the participatory uses of recorded media has been neglected (1998, p. 18).

We think it is not only a lack of imagination but also a lack of expertise in the development of visual learning strategies by those interested in the potential impact. The images (still images or moving images) do not emerge spontaneously. They are designed and produced deliberately. Innovative learning strategies develop from intuitive and theoretical design processes and are shaped in lengthy production processes. Cassin (1994) elaborates on the misconception of spontaneous art production as he proposes:

\begin{abstract}
Many people have a very romantic idea of how artists work. They imagine them for inspiration to strike, like some kind of benign lightning bolt. When this happens they are supposed to rush out to their studios and paint feverishly until the mood passes or the work is finished. The composition of a painting may sometimes appear fully formed in an artist's imagination, but more often it has to be thought out and designed. A painter may do this before he touches a brush or canvas or he may rely on his experience and allow the composition to develop as he works. In either case, the process is more complex than we might suppose from looking at the end result (1994, p. 2).
\end{abstract}

Although Cassin uses the slightly different perspective of a painter, his comment explains that the production of images is not always recognised for its craftsmanship. Producing film encompasses a variety of cinematographic practices, skills and competencies, but in addition it implies an array of technical, managerial and financial issues. Equally, it might be easily overlooked or underestimated that producing visual learning strategies is dealing with deliberate design. It is about a particular learning strategy that has to be elaborated according to set objectives. Added to this, there is always a sense of composition, editing and selection involved. Even a distant and neutral way of filming - if ever possible - is the result of a long series of decisions over issues such as camera perspectives, framing and timing. Whereas technicalities might be overlooked, there is often ample attention paid to the assumption that filming might be too intrusive to the "subjects" of the filming as compared to conventional research techniques of observation and interviewing. Mentioning this common "ignorance" of production and ethical issues in filming is not meant to discourage the realisation of the potential for visual learning, it is meant to provide arguments for a critical analysis of filming and using film for learning. Roberge $(2005$, p. 25) states that limitations on classifying (documentary) film "show both the complexity of the subject as the poverty of our theories." He adds to this in a kind of reversed mode by stating: "we can expect that if our films are not satisfactory our film theory is likely not to be satisfactory either" (Roberge, 2005, p. 26). Yet, to further complicate the issue of understanding film (and visual learning strategies), he writes: "when a political film is a fictional narrative film, 
then in order to convey its message that film must have a certain degree of perfection. That perfection in many instances is that of art" (Roberge, 2005, p. 112).

The Brazilian theatre director Augusto Boal, famous for his "Theatre of the Oppressed", published his explicit vision of the relevance of quality images and stories in his "Aesthetics of the Oppressed":

In our societies with the end of better oppressing the oppressed, the oppressor seeks to reduce the symbolic life of the oppressed, their imagination consigning them to mechanised work in which they are replaceable by any other - their names become numbers [...] The Aesthetics of the Oppressed aims at the liberation and fortification of metaphoric activity, of symbolic languages, of intelligence and sensitivity. It aims at the expansion of the perception that we have of the world. This is done through the Word, the Image, and the Sound, guided by Humanist Ethic (Boal, 2006, p. 43).

Interpreting Boal, his focus on "Aesthetics" is appreciated, yet further complicates the process of design and production of visual learning strategies as a broad set of competencies is required. When artistic and creative qualities are combined in the scientist and film maker, this may create new problems. Henny (1986) proposes role conflicts are almost inevitable from his perspective as a sociologist cameraman:

Conflicts between the moralist and the scientist, the academician and the journalist, the 'hard' empiricist and the 'weak' ethno methodologist, etc. It can be assumed, however that the sociologist who is a morally conscientious ethno methodologist with a knack for journalism will be more likely to find a humanizing use for audio-visual media than will his alter ego. His alter ego may, however, by the same token find cameras and monitors extremely useful for observing crowds, analysing crowd behaviour and subsequently deriving recommendations on crowd control to the Police department (1986, p. 55).

To conclude, in visual learning we define "visual" as a rich language that uses pictures or images of any type - even mental pictures - that create a look to the world, bring people and issues on stage, alter time, distances, places and spaces in a language that is metaphorical and narrative. This is in line with Woolner et al. (2010) discussing visual methods to engage users. The visual language analysed in this article calls upon the audience to listen, to experience and to become engaged in a mental process of reframing and reconsidering the representation and meaning of issues at stake. Visual learning strategies provide opportunities for learning which are not possible with traditional written/printed means, as films extend human experiences; they overcome physical limitations (Pinnington, 1991) and provide specific tools for reflection and mediation. The ability of visual media to alter distances of time and space can support the changing role of the audience from neutral observer, experts and researchers to engaged co-constructors of knowledge, as it may provide tools for observation, reflexivity and mirroring that are not catered for similarly in traditional textbased learning environments. 
We also conclude that the current absence of expertise and understanding regarding designing and producing visual learning strategies requires consideration by the various disciplines involved. Taking into account that educational design, art design and filmmaking are contributing fields, we may claim a focus on multidisciplinary aspects. The mentioned lack of good practices may also constitute then a reason to combine conventional academic research activities with design activities. In other words, to research new visual learning strategies they need to be designed and produced.

\section{Visual Problem Appraisal (VPA)}

A visual learning strategy is an operationalized approach to learning which makes use of visuals in a particular learning and instruction style. An example of such a visual learning strategy is the methodology of Visual Problem Appraisal (VPA) (Witteveen \& Enserink, 2007a, 2007b; Witteveen, Enserink \& Lie, 2009; Witteveen, Put \& Leeuwis, 2010). VPA is based on aspects of experiential learning. This means that reflection on one's own activities is emphasised in the learning process. VPA creates a safe space in which these kinds of reflections can be facilitated. It is a film-based learning strategy to enhance the analysis of wicked problems and facilitate a plan of action. It is used in workshops dealing with problem analysis and policy design, and involves the participants "meeting" stakeholders through the latter's filmed narratives. Contrary to Participatory Video (PV), a VPA is filmed by a professional film crew and seeks participation in the learning process and use of the films, not in the production of the films. VPA shares with PV that it is a methodology aiming to achieve social change by using video. For an overview and a typology of the different uses of video in development see Lie and Mandler (2009).

The filmed narratives and accompanying documentaries give the participants a chance to explore the complex and conflict-ridden arena of a particular issue. They follow a threestage programme: scoping, stakeholder consultation and action. The scoping stage varies from a quick scan to a desk study. "Meeting" stakeholders through the filmed narratives allows participants to learn about the stakeholder perspectives and problem analysis. During the "meetings", the participants view a selected number of interviews. The selection procedure simulates the reality of stakeholder consultation, where constraints of time, resources and access are influential. This procedure makes participants feel responsible as they realise their choices have important consequences.

VPA workshops create a space where interviewees tell their stories, filmed in a way that the audience experiences the role of listener and interviewer. The audience may feel sympathy, antipathy or confusion; these feelings are not simulated, but real, which becomes apparent during presentations when participants reveal their identification with their filmed informants by talking in terms of "we": "We first went to see Mr Reza" or "During the interview with us she said..." To foster mediated dialogue, VPA uses an interview-driven film 
style. The films are extended narratives with only the interviewee on screen in long steady frames filmed on location and during activities in his/her daily environment.

The first VPA set of its kind, "Rice from the Guyanas" (Witteveen, 2007; reprinted from 1996), focused on international agribusiness and rural development issues in the Guyanas. A second VPA set, "Kerala's coast" (Witteveen, 2003), was produced in Kerala, India, and focused on integrated coastal zone management. A third VPA set, filmed in Ghana, Tanzania and Zambia, focused on HIV/AIDS and rural development in sub-Saharan Africa (Witteveen, Lie \& Thachapuzha, 2008) and a fourth set on livelihoods in KwaZulu-Natal, South Africa, is expected to be ready in the course of 2012. VPA workshops have taken place in a variety of settings and countries. Participants in these workshops come from a wide variety of institutions, among which are policy makers, extension workers, NGO representatives, government representatives, BSc students, MSc students and PhD students. A distinction can be made between the use of VPA in a setting of formal (higher) education and using the VPA in the public domain. Using the VPA in formal education is also guided by the expected learning outcomes of their curriculum. The use of the VPA in the public domain takes place in a context of problem analysis and policy design. The "users" or participants are then directly engaged in a social learning process that is also explicitly guided by the agenda of the organisers.

\section{The value of using film in multi-stakeholder learning environments}

\section{Problem analysis}

Through the visual learning strategy VPA, the users learn about the complexity of the issue at stake. VPA users, such as future practitioners and secondary stakeholders, indicate that they learn about the substantive, strategic and institutional components of a problem (see Witteveen, Enserink \& Lie, 2009; Witteveen, Put \& Leeuwis, 2010). They experience the multi-stakeholder complexity and learn about the short- and long-term variations of problem definitions. VPA introduces or underlines the recognition that problems are "owned". Ownership of problems is attributed to stakeholders directly impacted by the (perceived) problem and indirect stakeholders; those with a mandate to act or otherwise have a functional relation to the issue at stake.

From the very start, when VPA users assess and therefore activate their expertise and existing knowledge, they feel intrigued with the problem and the issue at stake. In the scoping stage, VPA users analyse the problem. The depth and quality of the scoping stage may vary, as it depends on resources and time available; but basic scoping activities are required to enable VPA users to articulate substantive problem elements. The stakeholder consultation emphasises the strategic and institutional problem perspectives. The different tracks that are followed by the VPA groups during this stage create a sense of competition, as groups wish to assure their stakeholder selection and consultation are optimal. As VPA users realise that the option of different tracks might indicate a deficiency or accidental 
quality of their analysis, they feel responsible for justifying the process. This effect further enhances the problem analysis.It is the creation of a safe space through the VPA that helps to induce learning. The safe space tolerates uncertainty and allows contrasting or even conflicting information to circulate. This safe space has not been researched in detail, but to understand its functioning we assume that issues such as maintenance of face and prevention of embarrassment play a role. Interpreting the studies of Goffman (1967) on interaction rituals, these issues can be considered as conditions not as an objective of interaction.

We have experienced that VPA users, reflecting on their enhanced problem understanding, also report on their own learning processes. A major element of this (meta) understanding of problem analysis by the participants is the realisation that their previous constructions and perceptions of the problem were somehow naive and too straightforward. This enhanced problem analysis results from VPA as a whole; from the created space constituted by the films, from the reflective forms the participants need to complete, the learning strategy and the interactions between all participants. The identification with concerned stakeholders through the mediated encounter creates engagement. The continuous reflection and feedback on the process enhances the intrinsic motivation to come to terms with the issue at stake. This continuous focus on accountability for the process increases a sense of legitimacy for application of the outcomes among the users.

Especially in settings of formal education in the life sciences, the mediated stakeholder consultation provides valuable options for training or preparing students (future practitioners) for undertaking fieldwork in internships and thesis projects. Students, exposed to filmed resource people through VPA, have limited options to attribute problems to failing logistics, transport issues, cultural differences, language and other communication constraints. The filmed narratives are available and the students can observe and learn from them and reflect on their way of dealing with the problem analysis process.

In Witteveen and Lie (2009), we elaborated on learning in line with the concept of "creating positive friction" (Vermunt, 1992, p. 38) and the results of that study indicated that visual learning strategies can create such positive friction. Since facilitators or lecturers can observe the films beforehand and dispose of transcripts, they gain insight into the students' experiences and informative resources that would not be possible during real live or outdoor field activities of students. In a sense, VPA diminishes the number of variables affecting the quality of the students' analyses to one major variable that consists of the performance of the students. This enables the facilitator to provide students with direct and concise feedback on their work. The directness and preciseness of this feedback may be perceived as confrontational by the users or participants. But it leads to positive friction, as the quality of the feedback supports the future practitioners to reflect on possible misconceptions, omissions and other weaknesses that could otherwise be attributed by students to factors beyond their influence and control. Narrowing and even eliminating disputes on what internal or external factors are determining the quality of the problem analysis are experienced as very advantageous by VPA facilitators. It increases the focus on potential professional weak- 
nesses and failures, which is not a favourite subject for many students; but all too soon they convert this reluctance to a reflection and expression of learning objectives. Such a strong or deep learning experience makes students realise how they treat subjects of study as objects, make wrong interpretations, raise false expectations and intrude fragile livelihoods.

The no-escape character of VPA feedback loops sharpens the focus on harm that may result from unethical or weak professional practices. It is a harsh conclusion to state that in preparing students for fieldwork, some basic elements of ethics and intercultural communication with vulnerable and diverse stakeholders have often been disregarded in education. Manuals and textbooks on research do sometimes narrow down to issues of informed consent, whereas others elaborate in more detail on dilemmas of the encounter (Oliver, 2008, pp. 116-118; Thrift, 1993, p. 107). VPA provides an alternative to practice the procedures and ethics of interviewing and fieldwork. Similar effects have also been observed while using the VPA outside settings of formal education. VPA users in the public domain also learn from facilitators' feedback, though the setting is different. The relationship between VPA users and facilitators in the public domain is not hierarchically defined as in formal education. VPA users and facilitators in the public domain often have a shared interest in achieving outcomes that go beyond personal learning objectives.

Overall, we conclude that the learning environment created by VPA contributes to the enhancement of the quality of a problem analysis, as VPA provides mediated experiences and reflective processes that induce problem analysis.

\section{Social dialogue}

The visual learning strategy of VPA has a capacity to create a space for social dialogue. The adjective "social" in a conceptual definition of social dialogue refers here to interpersonal relations, to the content, to the process and to the intentional focus (Leeuwis, 2004, p. 148). VPA participants report on the stakeholder consultation in first person plural and identify themselves as interviewers and the filmed stakeholders as interviewees. This sense of realism creates for the audience the experience of meeting the Other. In a context of experiential learning, it means that the live experience is replaced by a mediated experience. This mediated, but still primary experience, is not a quality strictly deriving from the films. It is the co-construct of realism in the films and the real engagement coming together in a space for learning. When this aspect was assessed using VPA in formal education (Witteveen, Put \& Leeuwis, 2010), it was labelled as "the strength of the simulation" and was considered a threshold indicator for the visual learning strategy. A particular example of the co-construct of reality in the VPA is the interview selection in the stakeholder consultation stage. The selection determines the events to follow and participants are held accountable and feel responsible. As a result, independently of the live or mediated character of the interviews, the selection is a real decisive act. It was concluded that films designed, produced and used in a visual learning strategy that incorporates principles of experiential learning can replace the live experience with a mediated experience and still maintain the experience to be perceived 
as primary. Although the films provide a mediated experience, the associated emotions and perceptions of the user (individually and collectively) are real. VPA as such creates a space of (experiential) learning. In this space of learning, the users meet the Other in social dialogue.

The social dialogue results from the particular film style as well as from the activating process that incorporates the users in a process of change. The users do not watch the films as "couch potatoes", but feel part of a constructed dialogue. The VPA films represent the everyday discourse of social actors. The specific VPA interview-driven film style respects the complete narrative as it was delivered during recording. Editing maintains "mistakes", hesitations and repetitions in the narrative of the interviewee. In this way, interview conventions are contested and do not match the users' expectation, as they are mostly trained to consume parboiled arguments. As the VPA narratives unfold, the users realise they are to deconstruct and reconstruct the storyline. This adds to the experience of being part of the dialogue. As a result, they realise that the analysis of the discourse also reveals their own framing and understanding of the issue at stake. These effects occur in the observation and analysis of one single interview and are repeated and iteratively reinforced in the consecutive observation of a series of narratives.

It was realised that an additional value of using film for social dialogue is the option for repeated observation. This allows the users to see, hear and feel more of what is encapsulated in the film. This results from the richness of the visual strategy, as it is difficult to appreciate all information at a first look. It has been frequently observed that the user is initially keen on factual information. For instance, rather than observing and listening to the interviewee, the users may pay attention to their notebooks for factual note taking. This conventional focus on extracting information may hinder a more holistic or interpretive focus. Good listening to tone of voice, to concealed information or to meaningful gestures sometimes needs to be the instigated by the facilitators. This process of gaining insight into their usual way of observing also allows the users to reflect on their "normal" audience behaviour in a live situation. This reflection on mediated observation leads to social learning about their abilities and shortcomings as partners in a dialogue.

Overall, we conclude that the learning environment created by VPA contributes to initiating social dialogues, and these dialogues have social action and change on the agenda. The visual learning strategy creates social engagement between relevant actors.

\section{Mediated participation}

As a promising benefit of VPA, mediated participation was studied (Witteveen, Enserink \& Lie, 2009). This term was used to contrast live presence of silenced and overlooked stakeholders in processes of public participation. Mediated participation refers here to the filmed contribution (or mediated presence) of direct stakeholders who otherwise would not be present in public policy making processes. Initially, mediated participation was considered to be a second best option after live presence or participation. Throughout the study, the insight emerged that mediated participation is a concept worth considering for 
its autonomous relevance, as it may enhance social inclusion and equity in problem analysis and decision making by other means, such as through live participation.

Mediated participation allows altering perceived or tangible constraints, such as distance, scarce resources, an agenda loaded with productive and reproductive tasks, health problems or safety issues that impede on the participation of stakeholders in processes of public participation. Mediated participation removes these constraints from the primary stakeholder (e.g., the interviewee) and converts them into the responsibility of the filmmakers to produce a good selection of filmed narratives.

Other hindrances influencing the effective participation of stakeholders during a process of public participation, such as, language barriers and an array of socio-cultural issues, are converted, as filmed narratives change the resulting dialogue. This effect may not only be advantageous to the mediated stakeholders, but may also have advantages to the observer- stakeholders. VPA users commenting on their prejudices and biases did express a sense of shame upon realising how their inappropriate observations and analysis would have influenced the quality of a live dialogue. Mostly, participants realise they have a safe space for experimenting and learning, as their "errors" will not have negative consequences for involved stakeholders. Realising this freedom to learn and act by trial and error, provides a psychological space for learning and dialogue, which is absent in the reality of live stakeholder consultation or public participation. Facilitation may emphasise using this freedom wisely and ethically.

We learned that mediated participation also constitutes advantages for interviewees sharing delicate stories. It is appreciated that silenced and overlooked stories about issues such as commercial sex work, drunkenness, AIDS, poverty and social exclusion were contributed to the films produced in this research. Observing the effort primary stakeholders exert to externalise their stories, we realise that a single recording is of a high efficiency degree when watched by a great number of interested outsiders.

In the different VPA workshops, we have come across participants who expressed a wish to go beyond the filmed narrative of these delicate issues and establish a direct dialogue with concerned stakeholders. As it is not feasible to grant this wish, the underlying ambitions were then discussed and analysed and in our experience this could lead to discourse analysis of substantial quality. Particular examples derived from the VPA workshop "AIDS and Rural Development in Sub-Saharan Africa" in Bukavu, DR Congo. A group of VPA users discussed the reasons they wanted to find out how an HIV+ stakeholder was infected and they concluded that the answer was of no professional interest, instead it was grounded in personal curiosity or a combination. Another group questioned extra-marital relations and later discussed that extra-marital maybe was a quite erroneous term to use in a war-ridden situation, where many women never reach stable economic and affective relations with a man for reasons beyond their influence. As if inspired by Foucault (Hall, 1997, p. 43), they discussed that using the term extra-marital was maybe done to make themselves feel of a higher social status as they themselves were married with children of the same father-same mother relationships. 
Overall, we conclude that mediated participation should not be considered as a secondbest option to live participation. In particular, the VPA learning strategy offers a primary experience and an alternative to learning through face-to-face interactions. Consequently, visual learning strategies may enhance social inclusion and equity in problem analysis and decision-making. A similar conclusion is drawn by Braden (1998, p. 97) when commenting on groups "at the margins of society" to whom the public sphere was "relatively private". She reports that the realisation of common interest with others through video projects stretches the boundaries of their communities, leading to the transformation of the public sphere. Braden (1998) further concludes that although other media are available to make local people heard "beyond their immediate context", video records both sound and image and offers opportunities "for representation and dialogue through which excluded people can be heard in the public and semi-public spheres from which they have been marginalized" (p. 99).

\section{Considerations about the design, production and use of a visual learning strategy}

The value of visual learning strategies to achieve problem analysis, social dialogue and mediated participation results from the creation of a specific visual language through the use of film. In this section, we focus on critical conditions for interviewing and facilitating, and the processes related to designing and producing these visual languages.

\section{The art of interviewing}

A good interview is a treasure to cherish. Interviewing is a skill and an art and it requires preparation to be familiar with the context and to have a "better understanding of what might be left unsaid" (Slim \& Thompson, 1993). It is not a coincidence that social actors are willing to share their stories, especially regarding sensitive topics. It requires building rapport, making people feel at ease and creating space to let stories surface and to enable listening. It takes time to create a space of trust, openness and willingness to share the story of your life. Having created these narrative spaces, the interviewers, filmmakers and facilitators then have a serious responsibility to protect the stories.

We have often been asked to reveal how or why we managed to film interviews, which are assumed or experienced as difficult for reasons of gender, caste and other delicate issues such as AIDS prevalence. We have not found a definite answer to this, yet; we assume that it is probably a combination of our film making expertise and the motivation of social actors to express their stories. In line with research results reported by Ker Rault (2008, p. 256), we have experienced subjects' willingness to participate. Results from Ker Rault's study on public participation in integrated water management in the Levant indicated that the main reasons for involvement were to "give my opinion to the public authority about future plans and to exchange views with other citizens and stakeholders." More recently, the aspect of 
Article: Learning about "wicked" problems in the Global South

sharing with peers is gaining interest, as we heard from an interviewee filmed in the context of the VPA Rural Livelihoods in KwaZulu-Natal:

I have learned that talking heals me. If I talk about things that hurt me, if I talk the weight is reduced. And maybe if another person hears my story she would compare with hers and see that hers is better than this one. You see, sharing helps so that another person would see that she is not alone in that problem. And the other one will have hers that I bigger than mine. By talking, we are healing each other.

An emerging issue relates to ethics; i.e., the (moral) authority of filmmakers to record, store and "use" the stories of the interviewees and the competencies of interviewers and filmmakers to guarantee the integrity of the interviewee. Converting this in ample elaboration of informed consent formalities is only one alternative. Williams (2003, p. 169) departs openly from the idea that "informed consent must be violated to do a great deal of field research. [... ] Respondents cannot possibly be informed in such detail as to make them as knowledgeable agents as the researcher himself or herself". He therefore claims that "being ethical is a much more personal and subjective quality and is about [...] being able to reflexively evaluate the consequences of one's own actions on the lives of others" (Williams, 2003, p. 169). Informed consent means that the stakeholders agree on the film production and its use and sign a form articulating this consent. It is however recognised that it is more the quality of the consent procedure and the way of dealing with consent issues that makes social research earn credit for an ethical process (Thrift, 2003, p. 119).

Informed consent in the case of filming the VPA narratives was approached from a point of view focusing on procedures aiming to explain and ensure a particular use of the interview that provides basic information and contact details to enable the right of interviewees to withdraw permission. We have been careful not to promise anything we could not materialise. We have had a few opportunities to return filmed interviews to interviewees to show and give them a DVD with their interview. In those rare cases, the interviewees re-confirmed their consent. On the other hand, we also have refused all invitations to upload the films in open sources such as YouTube. This approach towards issues of consent also results from the interpretive stand of the involved filmmakers that it is their responsibility to deal ethically with the deposited confidence of the interviewees as they agreed to contribute to the filming. In this context, Williams (2003) states: "being ethical at this level is about a balance between science and commitment" (p. 169). To define what we mean by ethical, we follow the Credo for Ethical Communication of the National Communication Association (Andersen, 2000). One of the nine principles advocates "truthfulness, accuracy, honesty and reason as essential to the integrity of communication", and another principle underlines that "we accept responsibility for the short- and long-term consequences of our own communication and expect the same of others." Braden (1998) in this context mentions "rapport" to describe a "climate in which people work together with mutual respect and trust" (p. 88). Adding to this, a remark about the stakeholder selection is justified. In 
this study, ample time was allocated to stakeholder selection. Biases such as those derived from gender, social, class and caste, health status, age, and rural/urban biases were articulated and considered on various occasions. Departing from the notion that it is difficult to include actors you tend to overlook, all time dedicated to stakeholder selection has been appreciated as meaningful and ethically sound.

\section{The art offacilitation}

The initial assumption that using film in a learning environment could create a rather autonomous learning process whereby personal instruction is replaced by a mediated learning environment is not confirmed for VPA. Impact assessment shows that VPA creates a strong learning environment that requires sound facilitation. Since producing and using film in the social domain always seems to be incorporated in wider processes of learning and change, it seems reasonable to do further research on the facilitation of visual learning strategies. One of the issues we propose to research further is what we came to call "visual discourse analysis". In line with Foucault, who argues that "since we only have a knowledge of things if they have a meaning, it is discourse - not the things-in-themselves - which produces knowledge. (quoted in Hall, 1997, p. 45)", we imagine that we can create tools for visual discourse analysis that support the construction of meaning and lead to learning.

Another issue that requires more attention is the training of facilitators, as VPA carries new elements of facilitation and maybe also requires de-learning of obsolete competencies, such as "watching videos" differs substantially from "creating a learning space through VPA" as we are discussing here. An interesting example of a need to change perceptions on using visual learning strategies is exemplified in a passionate quote we received in a correspondence on a prospective VPA production:

\footnotetext{
It sounds nice, but is no good for our trainees. Our trainees should do such an exercise for real - otherwise they will not get it. The live interaction with interviewees, walking around at the farms, going to meet people with all kinds of different stakeholders in their offices, meeting the people in their workplace cannot be adequately substituted by watching video recordings! It really opens your mind if you can do all that, live the experience and not just talk and fake it in a classroom. We never do such things, although we talk about it (personal email correspondence, June 2009).
}

From this example, we learn that the VPA design principle of providing an alternative to fieldwork (Witteveen, Put \& Leeuwis, 2010) continually returns on the agenda when comparing mediated experiences with reality. In line with notions of "experiential learning", we elaborate in Witteveen, Put and Leeuwis (2010) that we consider VPA to be a simulation of reality that provides a mediated primary experience. The above quote is not taking into account this primary experience of analysis. VPA blurs the boundaries of the imaginative and the real situation and provides a simulation in cases where the above-mentioned "real" experiences are often not possible. As this experience results from dealing with mediated 
visuals and narratives, it might be worthwhile for facilitators to support visual discourse analysis by the participants during feedback activities. An interpretative semiotic approach may provide an entry point to have a better vision (Dick, 2010, pp. 360-361).

\section{The costs and benefits of visual learning}

Designing and producing films in the social domain, with a multi-disciplinary team, in a context of learning and change, remains a film production. Whatever compromise needs to be negotiated, if a film is to be produced, it is the visual language constituted by images, voices, sounds, the editing rhythm and other filmic elements that make it a film.

Regarding the efficiency of producing films in the social domain, we experienced that the costs required for producing film are often considered excessive. The VPA sets that were proposed, but not produced, may indicate that producing a VPA is experienced as costly in monetary terms of the budget. For the envisioned "VPA Hunze en Aa" (on water management in the Netherlands) and the "VPA Kadogo" (on the re-integration of child soldiers in DR Congo), budgets of around EUR 100,000 were established. Considering the production cost from a point of view of impact offers other options to frame the design and production cost. In other words, defining the costs and benefits of visual learning productions can be done from various angles, ranging from monetary perspectives to qualitative approaches. Although VPA is not a common product, which easily finds a market share, there might be a niche market if searched for, but even in that niche market we have found that it is not considered very usual to add a price to the product. Most often, it is expected that it is distributed for free. On the other hand, we have found that the shelf life of VPA is quite long. Most exemplary is the use of the "Rice from the Guyanas". Though filmed in 1996, it is still used in education. Although the context has changed, the basic issues remain valid.

A found footage experiment from a cost reduction perspective has been undertaken to test the feasibility of re-using footage for a VPA production that was shot for other documentaries. This experiment showed that the "recycling" idea is nice, but cannot stand hold and resulted in an expensive failure (see Witteveen, Enserink \& Lie, 2009). Fragmented production budgets such as with the "VPA AIDS and Rural Development in Sub-Saharan Africa" also seem to give rise to problems, as they lead to lengthy production processes and sometimes incompatible results. Another indication of limited understanding of filmmaking, through a focus on reducing budgets, were proposals for limited budgets wrapped up as approaches for "participatory video". These proposals were most often based on the premise that handing over a small camera to an inexpensive, non-filmmaker assistant would lead to the designed and desired final product. Another way to bow the knee for quality, were ideas to invite students to produce footage during their fieldwork. D'Antonio (1998) attributes this discrepancy between footage and an edited film to a lack of distance between filmmakers and the narrative when explaining how the footage for a documentary could not be edited. "They had captured the spirit in the footage but it was not communicated in the structure, the writing and the editing. Their knowledge and enthusiasm for 
the subject actually hampered bringing the material close to a view who was new to the story" (p. 253). D'Antonio (1998) recognises that "many documentaries do not start with a prewritten script, but it helps if the filmmaker has a story in mind while shooting. [... ] The point is to continually be thinking about the story and keeping that focus as much as possible while shooting. This will make life easier in the cutting room since footage needs to 'belong' to the story" (p. 254). Although the above quotes are most valid for documentary style of filming like the VPA documentaries, D'Antonio exemplifies with these comments the need to distinguish roles in the film making process and to value professionalism.

Considering the production of visual learning strategies as "expensive" may be attributed to a lack of knowledge and experience with film productions. Costs of educational design are often perceived as low, as most of the costs are incorporated in overhead expenses such as monthly salaries of involved staff. We have not found substantial information in the literature regarding this issue. From our experiences and the financial constraints, the recommendation is to guarantee a budget for the whole production. This will ensure a basic quality of the film production. We have learned more lessons on dealing with problematic budgets, such as the advantage of production insurances and the importance of reliable sound recording. They fall outside the scope of this article.

We have not extensively addressed the aesthetics of a "good film"; however it requires mentioning. Aesthetics and art delivered criteria during filming and editing that were though not always explicitly articulated or omitted to paper - of relevance and inspiration to the filmmakers.

\section{Conclusion}

The experiences obtained with Visual Problem Appraisal provide evidence that it is possible to design, produce and use a specific visual learning strategy to achieve strategic learning objectives that enhance complex competencies for action and change.

Visual learning strategies overcome physical, cultural and social barriers between vulnerable stakeholders and decision makers. The mediated encounters of the Other and other places and realities contribute to problem analysis, social dialogue and mediated participation. The value of these visual learning strategies in the context of wicked problems in multi-stakeholder settings and sustainable development make it relevant to design and produce specific film formats.

A fundamental feature in the production and use of films in the social domain for the realisation of the above-mentioned values is the consideration that a specific learning environment requires a particular film style or visual language. It is not film in general that defines the outcome of the learning process; it is the conceptual design, grounded in specific learning and film theories that lays foundations for the process that can be induced by film. Designing, producing and using existing and yet to innovate visual learning strategies require due attention, expertise and resources. 
We learned that if stories, people or practices are to be filmed with the articulated intention to bring other places, spaces and realities in the arena of social learning, it is not just any story that will provide new insights and induce dialogue. The film-making process should pay due respect to the (technical) quality required based on a grounded conceptual and educational design and flavoured with a sense of art or attractiveness. Achieving this quality requires appropriate competencies, which are not yet common in the social sciences.

\section{References}

Andersen, K.E. (2000). Developments in communication ethics: The ethics commission, code of professional responsibilities, credo for ethical communication. Journal of the Association for Communication Administration, 29: 131-144.

Boal, B. (2006). The aesthetics of the oppressed. New York: Routledge.

Braden, S. (1998). Video for development. A Casebook from Vietnam. UK and Ireland: Oxfam.

Cassin, M. (1994). More than meets the eye. A closer look at paintings in the National Gallery. London: National Gallery Publication.

D'Antonio, J. (1998). The audience representative. In M. Tobias (Ed.), The search for reality. The art of documentary filmmaking (pp. 253-256). USA: Michael Wiese Productions.

Dick, B.F. (2010). Anatomy of film. London: Palgrave Macmillan.

Giller, K.E., Leeuwis, C., Andersson, J.A., Andriesse, W., Brouwer, A., Frost, P., Hebinck, P., Heitkönig, I., Ittersum, M.K. Van, Koning, N., Ruben, R., Slingerland, M., Udo, H., Veldkamp, T., Vijver, C. van de, Wijk, M.T. van, \& Windmeijer, P. (2008). Competing claims on natural resources: what role for science? Ecology and Society 13(2): 34. Retrieved, 20 December, 2011 from: http://www.ecologyandsociety.org/vol13/iss2/ $\operatorname{art34/}$

Goffman, E. (1967). Interaction ritual. Essays on face-to-face behaviour. New York: Pantheon Books.

Hall, S. (ed.) (1997). Representation. Cultural representations and signifying practices. London: Sage Publications in association with the Open University.

Henny, L. (1986). Theory and practice of visual sociology. Current Sociology, The Journal of the International Sociological Association, doi:10.1177/001139286034003009.

Hermans, L.M. (2005). Actor analysis for water resource management. Putting the promise into practice. Delft: Eburon.

Hounkonnou, D. (2001). Listen to the cradle. Building from local dynamics for African renaissance. Case studies in rural areas in Benin, Burkina Faso and Chana. PhD thesis. The Netherlands: Wageningen University.

Ker Rault, P.A. (2008). Public participation in integrated water management - A wicked process for a complex societal problem. PhD thesis. U.K.: Cranfield University.

Leeuwis, C., \& Ban, A. van den (2004). Communication for rural innovation. Rethinking agricultural extension. USA and the Netherlands: Blackwell Publishing and CTA.

Lie, R., \& Mandler, A. (2009). Video in development. Filming for rural change. Wageningen, Rome: CTA, FAO.

Oliver, P. (2008). Writing your thesis, $2^{\text {nd }}$ ed. London: Sage Publications.

Pinnington, A. (1991). Using video in training and education. U.K.: McGrAW-HILL International. 
Robb, C.M. (2002). Can the poor influence policy? Participatory poverty assessments in the developing world. Washington DC: IMF and The World Bank.

Roberge, G. (2005). Another cinema for another society. Delhi: Seagull Books.

Slim, H., \& Thompson, P. (1993). Listening for a change: Oral testimony and development. London: Panos Publications Ltd.

Thrift, N. (1993). Practising ethics. In Pryke, M., Rose, G., \& Whatmore, S. (eds.), Using social theory. Thinking through research (pp. 105-121). London: Sage Publications in association with the Open University.

Vermunt, J.D. (1992). Leerstijlen en sturen van leerprocessen in het hoger onderwijs. Naar procesgerichte instructie in zelfstandig denken (Learning styles and regulating of learning in higher education. Towards process-oriented instruction in autonomous thinking). Lisse: Swets and Zeitlinger.

Wals, A.E.J. (Ed.) (2007). Social learning towards a sustainable world: Principles, perspectives, and praxis. Wageningen: Wageningen Academic Publishers.

Williams, M. (2003). Making sense of social research. London: Sage Publications.

Woolner, J., Clark, J., Hall, E., Tiplady, L., Thomas, U., \& Wall, K. (2010). Pictures are necessary but not sufficient: Using a range of visual methods to engage users about school design, Learning Environments Research, doi:10.1007/s10984-009-9067-6.

Witteveen, L. (2003). Visual Problem Appraisal Kerala's coast. Cochin, India: Aurora Visual Media; Wageningen, The Netherlands: Larenstein University of Applied Sciences; Delft, The Netherlands: Delft University of Technology; Cochin, India: Cochin University of Science and Technology (25 DVDs, 1 CD-ROM with facilitators' guide and workbook).

Witteveen, L. (2007; reprinted from 1996). Visual Problem Appraisal rice from the Guyana's. The Hague, The Netherlands: DIALOOG Produkties; Wageningen, The Netherlands: Larenstein University of Applied Sciences (15 DVDs, 1 CD-ROM with facilitators' guide and workbook).

Witteveen, L., \& Enserink, B. (2007a). Visual Problem Appraisal-Kerala's coast: A simulation for social learning about integrated coastal zone management, Simulation and Gaming, doi:10.1177/1046878107300667.

Witteveen, L., \& Enserink, B. (2007b). Cultural issues in making and using the Visual Problem Appraisal "Kerala's coast", Knowledge, Technology and Policy, doi:10.1007/BF02914893.

Witteveen, L., Lie, R., \& Thachapuzha, P. (2008). Visual Problem Appraisal AIDS \& rural development in sub-Saharan Africa. Cochin, India: Aurora Visual Media; Wageningen, The Netherlands: Larenstein University of Applied Sciences (14 DVDs, 1 CD-ROM with facilitators' guide and workbook).

Witteveen, L.M., Enserink, B., \& Lie, R. (2009). Mediated participation: using filmed narratives in complex multi-stakeholder settings, International Journal of Public Participation, 3(1): 32-62.

Witteveen, L., \& Lie, R. (2009). Embedded filming for social change. learning about HIV/AIDS and rural development professionalism, International Journal of Educational Development, doi:10.1016/j. ijedudev.2008.07.004.

Witteveen, L.M., Put, M., \& Leeuwis, C. (2010). Learning about complex multi-stakeholder issues: assessing the Visual Problem Appraisal, Journal of Agricultural Extension and Education, doi:10.1080/13892240903533145. 
Article: Learning about "wicked" problems in the Global South

Loes Witteveen

PhD, Lecturer

Van Hall Larenstein University of Applied Sciences Wageningen University and Research Centre, The Netherlands

Loes.Witteveen@wur.nl

Rico Lie

PhD, Assistant Professor

Communication and Innovation Studies Group

Wageningen University and Research Centre, The Netherlands

Rico.Lie@wur.nl 